\title{
THE IMPLEMENTATION OF M- COMMERCE IN SUPPLY CHAIN MANAGEMENT SYSTEM
}

Yousef A. Baker El-Ebiary Assoc. Prof.Dr., Faculty of Informatics and Computing, UniSZA (Malaysia) E-mail: yousefelebiary@unisza.edu.my

Najeeb Abas Al-Sammarraie Assoc. Prof..Dr., Faculty of Computer and Information Technology, MEDIU (Malaysia) E-mail:dr.najeeb@mediu.edu.my

Syarilla Iryani A. Saany Assoc. Prof.Dr. Faculty of Informatics and Computing, UniSZA (Malaysia) E-mail: syarilla@unisza.edu.my

Recepción: 05/03/2019 Aceptación: 05/04/2019 Publicación: 17/05/2019

\section{Citación sugerida:}

Baker El-Ebiary, Y. A., Al-Sammarraie, N. A. y Saany, S. I. (2019). The Implementation of M-Commerce in Supply Chain Management System. 3C Tecnología. Glosas de innovación aplicadas a la pyme. Edición Especial, Mayo 2019, pp. 222-239. doi: http://dx.doi. org/10.17993/3ctecno.2019.specialissue2.222-239

\section{Suggested citation:}

Baker El-Ebiary, Y. A., Al-Sammarraie, N. A. \& Saany, S. I. (2019). The Implementation of M-Commerce in Supply Chain Management System. 3C Tecnología. Glosas de innovación aplicadas a la pyme. Special Issue, May 2019, pp. 222-239. doi: http://dx.doi. org/10.17993/3ctecno.2019.specialissue2.222-239 


\section{ABSTRACT}

The progression of wireless technologies will dramatically and fundamentally transform the supply chain management, through the imminent mobile revolution. Many aspects of organizational life will be impacted by the revolution. Firstly, the crucial data will be presented in real time to help the decision makers while the ways businesses communicate, and the relationships with consumers and suppliers will dramatically change, all of which, will transform how the supply chain is managed. Issues related to the integration of Mobile Commerce (MCommerce) and Supply Chain Management (SCM) including the dearth of killer applications, mobile device limits, networking issues, infrastructure restrictions, security matters, and user distrust in mobile applications, are examined in this paper. There are also highlights on issues including usability, user interfaces, mobile access to databases, agent technologies, and models of mobile business.

\section{KEYWORDS}

Supply Chain Management (SCM), Information Systems (IS), E-Commerce, M-Commerce, Mobile Commerce, Wireless Technology. 


\section{INTRODUCTION}

Progresses in wireless technology and mobile devices have resulted in a novel

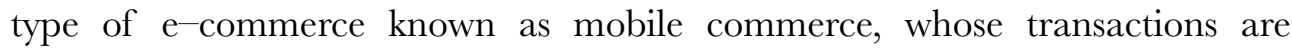
carried out with mobile devices through wireless telecommunication networks and other wired technologies associated with e--commerce. Mobile commerce or $\mathrm{m}-$-commerce offers users with ubiquity, personalization, localization, and convenience, and its application has expanded the Internet sales channels into mobile environments that are more direct and personalized. In the domain of business, the use of $\mathrm{m}^{-}$-commerce, therefore, offers incredible opportunities for the provision of value-added services to not only consumers but corporate users as well (Goolsbee \& Klenow, 2018).

The present paper looks into the mobile commerce application within supply chain management. For a company, its supply chain generally entails all stages that are directly or indirectly involved in meeting the demands of the customers (El-Ebiary \& Hilles, 2017). This chain of supply includes many parties including suppliers, manufacturers, transporters, warehouses, retailers, as well as customers. Inside a given organization, the supply chain for certain product or service involves each activity carried out by each precursor within the value chain for designing, generating, promoting, marketing, delivering, and supporting every individual constituent of that product or service. Hence, the aim of Supply Chain Management (SCM) is to connect the market-place, the network of distribution, the process of manufacturing and the activity of procurement, in a manner, that customers receive higher levels of services at a lower cost in total (Ciccullo, Caridi, Gosling \& Purvis, 2018).

Mobile Commence allows users access to the Internet irrespective of time and location. As such, its ability in detecting the location of an individual mobile terminal user in addition to its functionality in information access when necessitated can potentially decrease the administrative overhead while increasing efficiency (Hassan, Manna, El-Ebiary \& Al-Sammarraie, 2018). Not only that, the use of $\mathrm{m}^{-}$-commerce allows the information to be dispersed more quickly through 
the organization. With mobile commerce information exchange and purchases are possible and for a lot of parties linked to the supply chain, this is of use. For instance, in the context of customers, mobile commerce denotes convenience, while in the context of sales professionals, mobile commerce allows immediate sales, whereas, for managers who are on the move, mobile commerce enables communication and exchange of information. Mobile commerce, therefore, proves its ability in improving customer service, improving responsiveness, generating fresh channels of distribution, easing management of inventory, while also substantially improving the supply chain particularly in terms of performance (Hugos, 2018).

In essence, the organization of this paper follows the following structure: the ensuing section looks into the challenges in supply chain management, followed by a section that examines mobile commerce (Ciccullo, et al., 2018). Then highlights the mobile application challenges in supply chain management, while next elaborates the arising research issues in the integration of mobile commerce into supply chain management.

\section{CHALLENGES FOR SCM}

As can be referred to in Figure 1, the supply chain in a company usually includes countless departments and people, with information as the main determinant of supply chain management success. Along this chain, the products/services and funds flow to create information about massive quantities. At the same time, the information provides a direct linkage between customers and suppliers, and this allows real-time responses from the suppliers' side towards the market changes (Behzadi, O’Sullivan, Olsen \& Zhang, 2018). As such, the supply and demand for tailored goods can be appropriately matched at very brief time frames. In supply chain management, the function of information systems is to assure the accurateness and accessibility of the right information in a timely manner. 
The intense expansion of the Internet has also resulted in thriving e-commerce that has transformed how people execute their business, and such trend has equally presented fresh demands to the systems of the supply chain with features as detailed below:

- Information Sharing: The swift e-commerce expansion has resulted in the demand that corporations furnish more information to more internal users, and to certain outside vendors and customers as well. However, the traditional supply chain systems including ERP are mainly concerned with the internal operations including finance, human resources, and manufacturing which are accessible only to select users (El-Ebiary, Al-Sammarraie, Al Moaiad \& Alzubi, 2016).

- Optimization Focus: Supply chains are expanded with e-commerce has extended, and within the extended value chain, more optimization is needed bye-commerce. Relevantly, the conventional systems of the supply chain are aimed at optimizing the business processes within the company. Still, when considered from the viewpoint of the total value chain, the aforementioned processes may not be optimized (El-Ebiary, Najam \& Abu-Ulbeh, 2018).

- Internet Substitute. The emergence of the Internet has destroyed the longestablished notion that there exists a single system with the capacity to meet all needs of an organization. In fact, the functionalities of enterprise systems including payroll processing or transportation management could bit by bit be taken over by individual company of the Internet which offers a distinctive set of features linkable via a single inter-connected network (Alzubi, Alkhawlani \& El-Ebiary, 2017). 


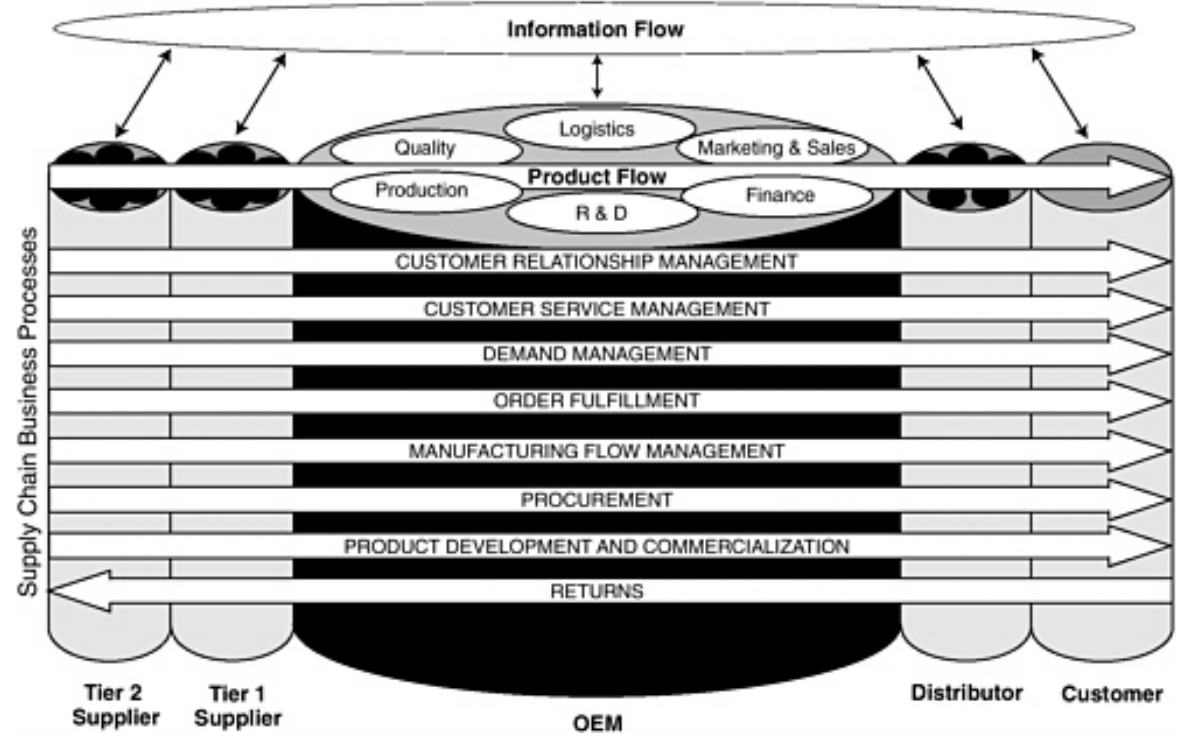

Figure 1. The Extension of Supply Chain and Supply Chain Flow.

Technology Obstacle. The incompatibility of hardware and software has caused an inability to a lot of the presently available supply chain systems in supporting interactive $\mathrm{e}^{-}$-commerce. Considering that the aim of these systems is to connect the application systems within the bounds of the enterprise, the established infrastructures support specific EDI protocols only (El-Ebiary, Abu-Ulbeh, Alaesa \& Hilles, 2018). For this reason, the aforesaid enterprise applications cannot become the basis for an $\mathrm{e}^{-}$-commerce infrastructure, considering that open standards are required by $\mathrm{e}^{-}$-commerce infrastructure.

\section{MOBILE COMMERCE}

Wireless and mobile networking is an entirely novel method that can be employed by companies in further expanding their supply-chain mobile commerce. The functions of $\mathrm{e}^{-}$-commerce are expanded through mobile commerce, resulting in the expansion of the $\mathrm{e}^{-}$supply chain system to the dimensions that were never aspired before. Mobile applications allow the user to access the supply chain system at all times and from all locations via the use of many different devices (e.g., cellular phones, PDAs, PCs, and TVs) (Hassan, Manna, \& El-Ebiary, 
2017). Accordingly, the concept of mobile commerce, its distinguishing features, important empowering technologies, and prospective applications are elaborated in this section to address the challenges facing supply chain management.

\subsection{DISTINCTIVE FEATURES}

Mobile commerce is essentially associated with reaching to the customers, suppliers, and employees, notwithstanding their location, and in fact, mobile commerce relates to the dispersal of the correct information to the correct time and location. This ability implies the flexibility of mobile commerce, and such flexibility is driven by the incorporation of the Internet, enterprise applications, and wireless technology. The distinctive features of mobile commerce are as described below:

- Ubiquity: Mobile devices enable business organizations to get to their customers anywhere at any time, while users are able to obtain any information that they seek, no matter where they are, with the use of Internet-enabled mobile devices. Mobile commerce, therefore, allows the provision of the needed service or application at all times and places.

- Personalization: The Internet is currently offering a massive amount of information, services, and applications, and the applicability of information received by users is of great significance. Also, considering that mobile devices owners frequently need diverse groups of applications and services, mobile commerce applications can be tailored to cater to the need of the specific user in terms of their desired information or services.

- Flexibility: Considering the portability of mobile devices, mobile users may perform transactions or receive information via their Internet-enabled mobile devices while engaging in other activities such as travelling.

- Dissemination: In a certain geographical area, there are wireless infrastructures that support instantaneous data delivery to all mobile users, offering an efficient way to deliver information to a vast population of consumers. 


\subsection{KEY M-COMMERCE ENABLING TECHNOLOGY}

Mobile commerce needs the development and deployment of the required facilitating technologies in order that it could expand substantially. Examples of these technologies include service technologies, network technologies, mobile personalization technologies, mobile commerce terminals, mobile middleware, mobile location technologies, as well as content delivery and format. Some of the leading technologies responsible for the materialization of mobile commerce are as follows:

- Global System for Mobile Communication orGSM: This technology is the dominant mobile standard in Europe and also in most part of the Asia-Pacific region, and this technology operates using the $900 \mathrm{MHz}$ and the $1,800 \mathrm{MHz}(1,900$ $\mathrm{MHz}$ in the USA) frequency band. GSM also has been the foundation for other technologies of the network, and these include HSCSD (High-Speed Circuit Switched Data) and GPRS (General Packet Radio Service). As GSM standard is widely adopted nowadays, the establishment of innovative mobile applications and services is economically practicable.

- Short Message Service or SMS: This technology allows the conveyance and reception of text messages to and from mobile phones. An SMS can contain 160 alphanumeric characters'maximum, in each exchange. The use of SMS is very common in Europe and the two major forms of SMS message are simple person-to-person messaging and voice mail notice. Additionally, SMS can contain mobile information services including news, weather updates, sports, stock quotes and so forth.SMS chat and ringing tones downloads are also available.

- Wireless Application Protocol or WAP: This technology encompasses an open and global standard for mobile solutions, involving the delivery of web information to mobile terminals. WAP entails an end-to-end application protocol and it presents resolutions to the issues that arise in the development of mobile applications. These include the connection of mobile terminals to the Internet and the transformation of mobile terminals into communication devices, with 
the capacity of communicating with other devices with the utilization of a wireless network. The design of interactive and real-time mobile services can be employed as well.

- Bluetooth: This technology encompasses a low power radio technology for the purpose of communicating and exchange of data. It is a low-cost short-range wireless standard utilizing a single chip with fitted radio-transmission circuitry, and it supports local area networks (LANs). Bluetooth is a replacement of cables and infrared links, and it can be used within a ten-meter diameter. With this technology, electronic devices (e.g., mobile devices, PCs, printers, and PDAs) can be connected to wireless data networks.

- Global Positioning System or GPS: Initially created for US military use, this technology encompasses a system involving satellites that orbit the earth. Satellites constantly broadcast their position and direction, and this allows the receivers of GPS to accurately identify the specific geographic location. The use of GPS is presently common among civilians, and GPS is most commonly employed in car navigation systems.

- eXtensible Markup Language or XML: This technology encompasses a metalanguage that was created for the purpose of conveying the data meaning with the utilization of a self-describing mechanism. XML tags data and places content into context, and this allows the providers of content to encode semantics into their documents. For XML compliant information systems, data can be directly exchanged even between organizations with dissimilar operation systems and data models but with the condition that the organizations are in agreement regarding the data meaning being exchanged.

- Wireless Markup Language or WML: This technology originates XML and its usage is for WAP especially. WML enables the representation of information in the form of cards that are appropriate for display on mobile devices. As a comparison, WML to WAP is HTML to the Internet. 


\subsection{MOBILE APPLICATIONS IN SCM}

Mobile commerce characteristics and its empowering technologies can increase the efficiency of information flows, and synchronise the operations within the extended enterprise. This will generate better supply chain management. Accordingly, the different uses of mobile commerce in prepping the organizations in facing the challenges in supply chain management are detailed as follows:

- Mobile email and Internet for corporate users: In wireless data usage, mobile email is the primary application, as it functions as the main line of communication for corporate users in order that they could remain connected with their organizations while travelling. Accordingly, the needed devices include a laptop, a GSM modem and a connected mobile phone, and corporate users use these devices to gain access to the mail server of the corporate network. Both mobile email and the mobile Internet allows the mobile professionals comprising sales professionals and customer care staff to engage in customer related tasks including tracking the order status, accessing the marketing information, checking the customer feedback, reporting the problems, consulting with the technicians, and identify the locations, irrespective of any time and anywhere. Similarly, mobile devices can be employed by field technicians in the communication of customer information, machine status, logistics, and order and billing information. Also, considering that mobile commerce enables instant data and exchange of information within organizations and among business associates, it eases the sharing of information and interactivity within the supply chain network, and this allows businesses to tackle the complex business environments.

- Mobile customer care: Through mobile commerce, customers can enjoy automated and independent operations directly from mobile terminals. UPS (United Parcel Services) is among the organizations that have started employing wireless devices in tracking shipments. Also, using PDA or mobile phone, customers can find out the estimated delivery time of their items. Additionally, mobility provides powerful channels to business units including financial institutions, to allow reaching out to their customers, via the use of 
mobile devices that are handy at all times. Mobile commerce essentially can intensify customer satisfaction through the push of information to mobile users, and place them in a superior informed position.

- Mobile enterprise implementations: Mobile commerce is usable in the management of logistics and workflow, as well as in streamlining inventory and the control of distribution. Bluetooth devices are an example of an appropriate inventory control tool - it allows automatic connection and communication, in place of manual connection. It is also easy to handle, in addition to fast data sharing and stock check, and sharing of stock data among supply chain members. For example, the use of Numoda which is a wireless provider, allows companies to gather and spread corporate data using handheld devices. Accordingly, wireless data gathering, instant wireless communication and exchange of information, and reporting and management of logistics and workflow are among the offered applications.

\section{MOBILE APPLICATION CHALLENGES IN SCM}

The potential of mobile commerce applications in the context of supply chain management may seem palpable. However, the success path may not be so simple. In fact, the real-world utilization of mobile commerce in the context of supply chain management can be inhibited by the technical limits of mobile devices and wireless communication, and business concerns. Hence in this section, the challenges that are faced by mobile commerce applications in the context of supply chain management are elaborated, as below:

- Absence of killer application(s): Within a computing platform, a killer application comprises an application that is sufficiently compelling in motivating purchases of that platform. In this regard, within the second half of the 1990s, access to the Internet is regarded as the killer application as it stimulates purchases of PC. Appositely, to assure the success of mobile commerce in supply chain management, it is important to add one or more killer applications in order to coerce organizations to acquire and utilize mobile devices in their day-to- 
day operations. It is crucial that the killer application(s) for mobile commerce comprehensively utilize mobility, furnish services that are directly applicable to mobile needs, and benefit users in terms of immediacy and efficiency.

- Mobile devices limitations: At the present time, the wireless devices consist of phones, laptops, computers (hand-held or palm-sized), and vehicle-mounted interfaces. Somehow, even though mobile terminals evidence a bigger scope of mobility and flexibility, in some respects, they seem inferior, as opposed to personal computers. For instance, mobile devices have a screen that is small while their display resolution appears to be low. Also, user input can be impeded by the small and multifunction keypad. Additionally, owing to the need to be light and small physically, the mechanisms of input and output appear to encumber the establishment of user-friendly interfaces and graphical applications for mobile devices. Besides that, the computational power, capacity of memory and disk, battery lifespan, and surfability, are among the limitations of mobile phones, as they do not support the multifaceted applications and transactions. Subsequently, they restrict the utilization of mobile commerce in this complex supply chain management environments.

- Incompatiblenetworks: In the cellular networkstandards today, there are numerous, complex and conflicting protocols. For instance, GSM encompasses a single standard utilized by the operators of the network in the Pacific Asian region and Europe. On the other hand, TDMA (Time--division multiple access) and CDMA (Code division multiple access) that employ different standards are widely utilized in the US. Owing to the differences of this used standard, there are discordancy among cellular phones globally, which cause problems to organizations in communicating and cooperating with their suppliers, distributors, retailers, as well as customers.

- Competing for web languages: There are a number of rival web languages available today. For instance, newer mobile phones operate on WAP and its WML. Conversely, NTT DoCoMo's iMode employs condensed Hyper-Text Markup Language or HTML. The use of incompatible standards in mobile devices today has increased the challenges in the establishment of successful 
applications of $\mathrm{m}^{-}$-commerce. Meanwhile, the increase in the number of companies that integrate mobile commerce with supply chain management has greatly intensified the need for having standardized web languages. Indeed, the problem of contending web languages needs to be tackled, in order to significantly improve mobile communications within organizations, and also the interactions between organizations and their business associates.

- Security concerns: Wireless communications appear to have a higher vulnerability, as opposed to wired communications. Notably, wireless data networks today mostly offer judicious encryption and security levels. Somehow, within the network infrastructure, the technology does not ensure the security of transmission. For instance, malfunctions of the mobile terminal can cause data loss, and these terminals can even be stolen while the ongoing transactions can be changed. In other words, the mobility of $\mathrm{m}-$-commerce also brings a lot more perplexing security tasks. Considering that the applications of mobile commerce are increasingly integral in supply chain management, addressing the security issue highly crucial.

- User distrust: The parties involved in any transaction, need to have the capacity in authenticating their counterparts. This is to assure that the received messages are not disturbed, the communication content remains confidential, and that the received messages originate from the right senders. However, considering that the mobile environment is essentially vulnerable, mobile commerce users appear to show great concern towards the issues of security in mobile transactions. It is therefore important that mobile commerce users are guaranteed their financial information security, and of the security of the wireless transaction. Trust of users towards mobile commerce is crucial in order that the mass adoption of mobile commerce in supply chain management can be achieved. 


\section{CONCLUSION}

Supply chain management can be positively impacted by mobile commerce. Still, there are several technical, regulatory, and social issues that need to be addressed. In the coming years, however, mobile devices are expected to continue developing, with the incorporation of more functionality. Expectantly, mobile commerce will be incorporated in supply chain management in numerous aspects. 


\section{REFERENCES}

Alzubi, M. M., Alkhawlani, M. A. \& El-Ebiary, Y. A. B. (2017). Investigating the factors affecting University students'e-commerce intention towards: a case study of Jordanian universities. Journal of Business and Retail Management Research, 12(1).

Behzadi, G., O’Sullivan, M. J., Olsen, T. L. \& Zhang, A. (2018). Agribusiness supply chain risk management: A review of quantitative decision models. Omega, 79, pp. 21-42.

Giccullo, F., Pero, M., Garidi, M., Gosling, J. \& Purvis, L. (2018). Integrating the environmental and social sustainability pillars into the lean and agile supply chain management paradigms: A literature review and future research directions. Fournal of Cleaner Production, 172, pp. 2336-2350.

Giccullo, F., Pero, M., Garidi, M., Gosling, J. \& Purvis, L. (2018). Integrating the environmental and social sustainability pillars into the lean and agile supply chain management paradigms: A literature review and future research directions. Fournal of Cleaner Production, 172, pp. 2336-2350.

El-Ebiary, Y. A. B. \& Hilles, S. M. (2017). Detection of Spam on Amazon $\mathrm{E}$-commerce platform. International Journal on Contemporary Computer Research (IfCCR), 1(3), pp. 15-21.

El-Ebiary, Y. A. B., Abu-Ulbeh, W., Alaesa, L. Y. A. \& Hilles, S. (2018). Mobile Commerce in Malaysia-Opportunities and Challenges. Advanced Science Letters, 24(6), pp. 4126-4128.

El-Ebiary, Y. A. B., Al-Sammarraie, N. A., Al Moaiad, Y. \& Alzubi, M. M. S. (2016). The impact of Management Information System in educational organizations processes. IEEE Conference on $e$-Learning, $e-$ Management and $e-$ Services (IC3e), Langkawi, pp. 166-169.

El-Ebiary, Y. A. B., Najam, I. S. M. \& Abu-Ulbeh, W. (2018). The Influence of Management Information System (MIS) in Malaysian's Organisational Processes - Education Sector. Advanced Science Letters, 24(6), pp. 4129-4131. 
Goolsbee, A. D. \& Klenow, P.J. (2018). Internet rising, prices falling: Measuring inflation in a world of e-commerce. In AEA Papers and Proceedings, 108, pp. 488-492.

Hassan, A. H., Manna, R. F. \& El-Ebiary, Y. (2017). The Effect of Trust Based Factors on Using Mobile Commerce in Jordan. International fournal on Contemporary Computer Research (IFCCR), 1(2), pp. 1-7.

Hassan, A. H., Manna, R. F., El-Ebiary, Y. A. B. \& Al-Sammarraie, N. A. (2018). Evaluating Trust-Based Factors Influencing Uses M-Commerce in Jordan. Advanced Science Letters, 24(6), pp. 4308-4311.

Hugos, M. H. (2018). Essentials of supply chain management. U.S.A.: John Wiley \& Sons. 
Edición Especial Special Issue Mayo 2019

DOI: http://dx.doi.org/10.17993/3ctecno.2019.specialissue2.222-239 